\title{
AS EDIÇÕES E AS TRADUÇÕES DA "CRÔNICA DOS FEITOS DA GUINE".
}

Em 1837, na Biblioteca Nacional (então Real) de Paris, Ferdinand Denis fêz um achado de grande importância para a clarificação da polêmica - tão pouco científica - que se travava à volta da prioridade dos descobrimentos portuguêses do século XV. Ferdinand Denis (1) encontrara o manuscrito da Crônica dos feitos de Guiné de Gomes Eanes de Zurara, única obra contemporânea do Infante $\mathrm{D}$. Henrique em que se relatam os seus descobrimentos africanos. O achado de Ferdinand Denis foi tanto mais sensacional quanto se tratava de manuscrito há longos anos perdido. A única referência que dêle havia, e certamente de exemplar bastante adulterado, era de João de Barros nas Décadas da Ásia (2) no segundo quartel do século XVI. Damião de Góis em 1567 já não sabe do seu paradeiro.

A êste achado outros se seguiram, embora de menor importância. Em 1847 J. A. Schmeller descobre em Munique o Codex monacensis hispanicus 27 na Bayerische Staats-Bibliothek, Handschriften-Abteilung, o qual veio a ser editado em 1940, com a leitura de Antônio Baião, pela Academia Portuguêsa da História, com o título: O Manuscrito Valentim Fermandes. Nesta coletânea há um texto intitulado Crônica da Guiné que é indiscutivelmente um resumo e arranjo do Manuscrito de Paris da mesma Crônica feito em 1506 pelo próprio Valentim Fernandes (3). Alguns anos mais, e em 1879 Ernesto do Canto revela a existência de cópias do Manuscrito de Paris em Madrí e em Munique, sendo a de Madrí do século

(1). - Ferdinand Denis anunclou o seu achado a páginas $43-45$ do 2.0 volume das Chroniques chevaleresques de l'Espagne et du Portugal, Paris, 1839.

(2). - Asia, Década 1a., Livro I.

(3). - Ver a demonstração no nosso trabalho: A mentalidade, o tempo e os grupos sociais (Um exemplo português da época dos descobrimentos: Go. mes Eanes de Zurara e Valentim Fernandes), in Revista de História, n.0 15, São Paulo, julho-setembro de 1953; ou na nossa versão abreviada dês: te mesmo trabalho: Mentalités, Temps, Groupes Sociaux (Un exemple portugais), in Annales - Economles-Sociétés-Civilisations, n.० 4, Paris, Octobre-Décembre 1953 . 
XVII e a de Munique do século XVIII. De simples cópias se trata, pois a comparação minuciosa com o Manuscrito de Paris apenas revela diferenças na letra e na ortografia, muito mais recentes as dêstes últimos.

E' sôbre o manuscrito da Biblioteca Nacional de Paris (4) - e muito justamente, pois é o mais antigo e completo - que a ação da crítica se tem exercido. Mais de trinta trabalhos, uns extensos, outros nas dimensões de artigos de jornal e revista, se escreveram até hoje, na mira de tudo tirar do achado de Ferdinand Denis. Se considerarmos a bibliografia, que embora não tenha como objetivo fundamental a Crônica dos feitos de Guiné, a ela se refere e às vêzes largamente, somos levados a ter em conta uma bibliografia que ascende a uma centena de pequenos e grandes trabalhos, alguns de mérito invulgar, como os de Joaquim de Carvalho (5), Costa Pimpão (6), Duarte Leite (7), Margarida Barradas de Carvalho (8) .

Outrotanto não poderemos dizer das edições portuguêsas que até agora foram realizadas de tão importante fonte para a História dos Descobrimentos e da Expansão Portuguêsas

A célebre Crônica de Gomes Eanes de Zurara foi editada pela primeira vez em 1841, em Paris, com Introdução e Notas do Visconde de Santarém, um glossário de Inácio Roquete, e com o título: Chronica do Descobrimento e Conquista de Guiné... Esta primeira edição - como aliás era inevitável - está desde há muito ultrapassada, não só no que se refere ao comentário crítico, mas mesmo no que diz respeito ao próprio texto, onde faltam palavras, e algumas vêzes quase linhas inteiras.

Em 1937 surge a segunda edição, no Pôrto, em 2 volumes, da autoria de José de Bragança, e com o título: Crônica do Descobrimento e Conquista da Guiné, segundo o manuscrito da

\footnotetext{
(4). - Seç̧ão de manuscritos da Biblioteca Nacional de Paris, Catálogo dos Manuscritos Portuguêses, n.o 41, antigo 42.

(5). - Sôbre a erudição de Gomes Eanes de Zurara (Notas em tôrno de alguns plágios dêste cronista), in Estudos sôbre a Cultura Portuguêsa do século XV, Coimbra, 1949

(6). - Alvaro Júlio da Costa Pimpão em vários trabalhos se ocupou da Crônica de Zurara, podendo nós citar como o mais importante: A "Crônica dos feitos de Guiné" e o manuscrito Cortez-D'Estrées, Lisboa, 1939.

(7). - Tal como Costa Pimpão, Duarte Leite dedica vários trabalhos a Zurara e à Crônica dos feitos de Guiné, sendo de todos o mais importante: Acêrca da "Crônica dos feitos de Guiné", Lisboa, 1941.

(8). - L'idéologie religieuse dans la "Crônica dos feitos de Guiné" de Gomes Eanes de Zurara, in "Bulletin des Etudes Portugaises et de l'Institut Francais au Portugal", tomo XIX, 1956.
} 
Bibłioteca Nacional de Paris, modernizada, com notas, glossário, e uma introdução... Mas, apesar de no título aparecer a indicação de ter sido feita segunldo o manuscrito da Biblioteca Nacional de Paris, a verdade é que ela foi feita segundo a velha edição de Paris, de 1841, do Visconde de Santarém, apenas com algumas correções segundo o manuscrito de Paris quando os erros da edição de Santarém eram por demais evidentes à simples leitura.

Vejamos alguns exemplos em que José de Bragança copia formas da edição do Visconde de Santarém que não coincidem com as do Manuscrito de Paris:

- Edição Santarém: "Semelhantemente el Rey dom Ramiro,...". (Cap. 1. ${ }^{\circ}$, p. 6).

- Edição José de Bragança: "Semelhantemente el-rei D. Ramiro,...". (Cap. 1.0, p. 13).

- Manuscrito de Paris: "Semelhauelmente elRey dó Ramiro,...". (Cap. $1 .^{\circ}$, f. 8) .

- Santarém: "...nom sem proveito do insino de todollos principes que seguirem o teu exempro;...". (Cap. $2 .^{\circ}$, p. 9).

- Bragança: "... não sem proveito do ensino de todos os Principes que seguirem o teu exemplo;...". (Cap. 2.0, p. 16).

- Ms. de Paris: "...nom sem proueitoso insino de todollos principes q. seguirem o teu exempro;...". (Cap. 2.․ f. $8 \mathrm{v}$.).

- Santarém: “... outros saude nos corpos, e escaramento de perigoos,...". (Cap. $2 .^{\circ}$, p. 13).

- Bragança: "...outros, saude nos corpos e esearmento de perigos,...". (Cap. 2.0, p. 20).

- Ms. de Paris: "...outros saude nos corpos, e escapamento de perigoos,...". (Cap. $2 .^{\circ}$, f. 9v.).

- Santarém: "E os seus golpes assiinados forom em aquelle dya antre todollos outros, ca per espaço de cinquo horas pellejou contynuamente, " (Cap. 5. , p. 26).

- Bragança: "E os seus golpes, assinalados foram em aquele dia antre todolos os outros, que por espaço de cinco horas pelejou continuamente;...". (Cap. 5..$^{\circ}$ p. 38).

- Ms. de Paris: " $\mathrm{E}$ os seus golpes assijnados forom em aquelle dya antre todollos outros, ca per espaço de cinquo horas pellejou contynuadamente, " (Cap. 5. $\circ$, ff. 13v.-14).

- Santarém: "Certamente nom som eu aquelle que esto seriba ". (Cap. 6. ${ }^{\circ}$, p. 42 ). 
- Bragança: "Certamente não sou eu aquele que isto escreva...". (Cap. 6. ${ }^{\circ}$, p. 56).

- Ms. de Paris: "Certamente nó som eu aquelle que esto saiba...". (Cap. 6. ${ }^{0}$, f. 19) .

- Santarém: "A condiçom da plebe, como diz Titollivyo, sempre he prasmarem de grandes feitos,...". (Cap. 18. ${ }^{\circ}$, p. 103).

- Bragança: "A condição da plebe, como diz Tito Livio. sempre é prasmarem de grandes feitos,...". (Cap. 18. ${ }^{\circ}$, p. 117).

- Ms. de Paris: "A condiçom da plebe, como diz Titollivyo, sempre he prasmarem os grandes feitos...". (Cap. 18.0, f. 38).

- Santarém: "Aquelle anno...". (Cap. 29.0, p. 151).

- Bragança: "Aquele ano...". (Cap. 29.0, p. 177).

— Ms. de Paris: "Naquelle ãno...". (Cap. 29.0, f. 55v.).

- Santarém: “...os capitaães muy allegres seguyrom em seus batees...". (Cap. 32. , p. 166).

- Bragança: "...os capitães mui alegres seguiram em seus bateis,...". (Cap. $32 .^{\circ}$, p. 193).

- Ms. de Paris: “...os capitaães muy allegres sayrom em seus batees,...". (Cap. $32 . \%^{\circ}$, f. 60).

- Santarém: " $E$ assy foe a presa daquella noite Liijo Mouros". (Cap. 38..$^{\circ}$ p. 192).

- Bragança: "E assim foi a presa daquela noite Lll Mouros". (Cap. 38. , p. 227).

- Ms. de Paris: "E assy foe a presa daquella noite Liiijo mouros". (Cap. 38.0, f. 70).

- Santarém: "O outro dya fezerom seu caminho,...". (Cap. 47. ${ }^{\circ}$, p. 221).

- Bragança: "O outro dia fizeram seu caminho,...". (Cap. 47. ${ }^{\circ}$, p. 261).

- Ms. de Paris: "No outro dya fezerõ seu caminho,...". (Cap. 47..$^{\circ}$ f. $79 \mathrm{v}$. ).

Vejamos agora alguns exemplos em que José de Bragança, seguindo a edição do Visconde de Santarém, salta palavras e algumas vêzes mesmo quase linhas inteiras do Manuscrito de Paris:

- Santarém: “...specialmente pellos grandes serviços que o dicto sñor sempre fazera aos reis passados, e polla grande bem feitoria que pollo seu aazo receberom seus naturaaes". (Cap. $1 . \circ$, p. 3). .

- Bragança: “...especialmente pelos grandes serviços que o dito senhor sempre fizera aos reis passados e pela grande bemfeitoria que pelo seu azo receberam seus naturaes". (Cap. $1 .^{\circ}$, p. 9). 
- Ms. de Paris: “... specialmente pellos grandes serviços q. o dicto sñor sempre fazera aos reis passados e a elle e polla grande bem feituria q. pollo seu aazo receberõ seus naturaaes". (Cap. 1.0, f. 6v.).

- Ms. de Paris: "E vendo depois os q. vierom como a lembrança das injuryas he tenra,...". (Cap. $1 .^{\circ}$, p. 5).

- Bragança: "E vendo depois os que vieram como a lembrança das injurias é tenra,...". (Cap. 1. ${ }^{\circ}$, p. 12).

- Ms. de Paris: "E veñdo depois os q. vierom como a lembrãça das injuryas sempre he tenra,...". (Cap. $1.0^{\circ}$, f. $7 \mathrm{v}$.) .

- Santarém: “...o menos que por sy daryam seryam dez Mouros, e que milhor era salvar dez almas que tres,...". (Cap. 16. ${ }^{\circ}$ p. 94).

- Bragança: "...o menos que por si dariam seriam dez Mouros; e que melhor era salvar dez almas que tres,..." (Cap. 16. ${ }^{\circ}$ p. 108).

- Ms. de Paris: “...o menos q. por sy daryam seryam dez mouros negros e q. milhor era salvar dez almas que tres,...". (Cap. $160^{\circ}$, f. $35 \mathrm{v}$.).

- Santarém: "....as quaaes parece se ajuntavam ally pera criarem,...". (Cap. 17. ${ }^{\circ}$, p. 102).

- Bragança: "...as quaes parece se ajuntavam ali pa. ra criarem,...". (Cap. $17 .^{\circ}$, p. 115).

- Ms. de Paris: “...as quaaes parece que se ajuntavam ally pera criarem,...". (Cap. 17.0, f. 37v.).

- Santarém: "E em buscando acharom vij. ou vij. Mouras,...". (Cap. 20. , p. 118).

- Bragança: "E em buscando, acharam VII ou VIII Mouras,...". (Cap. 20.0, p. 134).

- Ms. de Paris: "E em a buscando acharõ vij. ou mouras...". (Cap. 20. o, f. 44).

- Santarém: "...os primeiros que em sua propria terra forom filhados per xpaãos,...". (Cap. $31 .^{\circ}$, p. 159).

- Bragança: "...os primeiros que em sua propria terra foram filhados por Cristãos,...". (Cap. 31. ${ }^{\circ}$ p. 186).

- Ms. de Paris: "...os primeiros negros que em sua propria terra forõ filhados per xpaãos,...". (Cap. 31.0 , f. 58 ).

- Santarém: "...quando virom hum homem que estava em terra contra elles". (Cap. 34., p. 171).

- Bragança: "...quando viram um homem que estava em terra contra eles". (Cap. $34 .^{\circ}$, p. 200).

- Ms. de Paris: "...quando virõ hum homem que estava em terra braadando contra elles". (Cap. 34. ${ }^{\circ}$, $f$ $62)$.

- Santarém: “...como aquella gente se passara a as outras Ilhas,...". (Cap. $47 .^{\circ}$, p. 222). 
- Bragança: “... como aquela gente se passara às outras Ilhas,...". (Cap. 47.0, p. 262).

- Ms. de Paris: "...como aquella gente se passara Mas almaadyas a as outras Ilhas,...". (Cap. 47.0, f. 80).

- Santarém: "...e se desposesse aa pelleja com tal voontade como dissemos,...". (Cap. 60, p. 288).

- Bragança: "...e se disposesse á peleja com tal vontade como dissemos,...". (Cap. 60., p. 76).

- Ms. de Paris: "...e se desposesse aa pelleja com tal voõtade como ja dissemos,...". (Cap. 60..$^{\circ}$ f. 101v.).

- Santarém: "...e pois ja das outras disse como se tornarom pera o regno,...". (Cap. 64. ${ }^{\circ}$, p. 309).

- Bragança: "...e pois já das outras disse como se tornaram para o Reino,...". (Cap. 64..$^{\circ}$ p. 97).

- Ms. de Paris: "...e pois ja das outras disse como se tornarõ Lourenço dyaz e Gomez pirez pera o regno,...". (Cap. 64..$^{\circ}$ f. 107v.).

- Santarém: "...e muyta carne de porcos monteses que tiinham assada". (Cap. $75 .^{\circ}$, p. 357).

- Bragança: "...e muita carne de porcos montezes que tinham assada". (Cap. $75 .^{\circ}$, p. 155).

- Ms. de Paris: “...e muyta carne de porcos monteses que tiinham morta e assy outras veaçooens da qual alguma tijnham assada". (Cap. 75..$^{\circ}$ f. 125).

- Ms. de Paris: "E na seista ilha q. he de Tanarife, ou do Inferno, porque tem em cima hum algar...". (Cap. 79. ${ }^{\circ}$, p. 375).

- Bragança: "E na sexta ilha, que é de Tanarife, ou do Inferno, porque tem em cima um algar...". (Cap. 79..$^{\circ}$ f. 178)

- Ms. de Paris: "E na seista ilha q. he de Tanarife, ou do Inferno e chamãlhe assy do Inferno porque tem em cima hum algar...". (Cap. 79.0, f. 130).

- Santarém: "...e por lhe nom parecer lugär pera fazer presa, tornaronse outra vez a sua caravella". (Cap. 87..$^{\circ}$ p. 407).

- Bragança: "...e por the não parecer lugar para fazer presa, tornaram-se outra vez a sua caravela". (Cap. 87. ${ }^{\circ}$, p. 214).

- Ms. de Paris: “...e por lhe nõ parecer lugar aazado pera fazer presa, tornaronse outra vez a sua caravella". (Cap. 87..$^{\circ}$ f. 141).

- Santarém: "...e muyto mais por que fora sem alguma perda". (Cap. $900^{\circ}$, p. 427).

- Bragança: "...e muito mais porque fora sem algima perda". (Cap. 90.0, p. 236).

- Ms. de Paris: "...e muyto mais por q. fora sem alguma sua perda". (Cap. 90.\%, f. 148). 
- Santarém: "Quanto, disse elle, se vós querees veer Boor, que he o nosso grande rey,...". (Cap. 94. p. 444).

- Bragança: "Quanto - disse ele - se vós quereis ver Boor, que é o nosso grande rei,...". (Cap. 94. ${ }^{\circ}$ p. 254).

- Ms. de Paris: "Quanto, disse elle, se vós querees principalmente veer Boor, que he o nosso grande rey,...". (Cap. $94 .^{\circ}$, f. 153v.).

Vejamos finalmente alguns exemplos em que José de Bragança corrige alguns erros, por demais evidentes, do texto da edição de Santarém. Segundo as notas em fim de página em que José de Bragança explica as correções, podemos concluir que mesmo nestes casos a correção nem sempre foi feita segundo o manuscrito:

- Santarém: "...ca nenhum principe nom pode seer grande, se elle nom regra sobre grandes, nem rico, se nom senhorea sobre ricos;...". (Cap. 1.0, p. 5).

- Bragança: "...que nenhum principe não pode ser grande se ele não reina (1) sobre grandes; nem rico se não senhorea sobre ricos". (Cap. 1.0, p. 11).

"(1) - Na 1a. edição: regra, ou por má leitura de regna ou por êrro do próprio manuscrito".

- Ms. de Paris: "...ca nenhum principe nom pode seer grande, se elle nõ regna sobre grandes, nem rico, se nõ senhorea sobre ricos;...." (Cap. $1 .{ }^{\circ}, f$. 7).

- Santarém: " $E$ foe o filhamento della cidade huma quinta feira $\mathrm{XXj}$. dyas do mes dagosto, anno de Xpo de mil e n..$^{\circ}$ ". (Cap. 5., p. 27).

- Bragança: " $E$ foi o filhamento dela, cidade, uma quinta-feira XXI do mes de agosto, ano de Cristo de mil e quatrocentos quinze" (1). (Cap. 5. ${ }^{\circ}$ p. 39) .

"(1) - A 1a. edição traz aqui um evidente êrro de leitura, pois imprimiu ny. ${ }^{\circ}$, quando no manuscrito deve ler-se iij.cxv".

- Ms. de Paris: "E foe o filhamento della cidade huma quinta feira $x x j$. dyas do mes dagosto, anno de $\mathrm{Xpo}$ de mil e iiij.cxv". (Cap. 5. ${ }^{\circ}$, f. 14).

- Santarém: "Leixou muy nobres casas ao estado de Lixboa,...". (Cap. 5..$^{\circ}$ p. 31).

- Bragança: "Leixou mui nobres casas ao Estudo de Lisboa (3),...". (Cap. 5.०, p. 43).

"(3) - A 1a. edição diz: estado de Lixboa, o que é evidente êrro de leitura ou do copista". 
- Ms. de Paris: "Leixou muy nobres casas ao estudo de Lixboa,...". (Cap. 5..$^{\circ}$ f. 15v.).

- Santarém: "...todollos eixos dos ordes superiores...". (Cap. 25..$^{\circ}$ p. 132).

- Bragança: "...todollos eixos dos ordes (1) superiores,...". (Cap. 25. , p. 151).

"(1) - A edição original diz assim, mas talvez orhes seja lição preferível".

- Ms. de Paris: "...e todollos eixos dos orbes superiores,...". (Cap. 25..$^{\circ}$ f. $48 \mathrm{v}$.).

- Santarém: "Na outra ilha da Palma moram .V. homeens". (Cap. 19. ${ }^{\circ}$ p. 375).

- Bragança: "Na outra itha de Palma moram quinhentos homens (1). (Cap. 79., p. 177).

“(1) - A 1a. edição traz: V homens. E' êrro evidente, que emendamos de acôrdo com o que se lê adiante, cap. LXXXII".

- Ms. de Paris: "Na outra ilha da Palma moram .V.s homeens". (Cap. 79. ${ }^{\circ}$, f. 130).

Lembremos finalmente a única parte válida desta edição de José de Bragança: a Introdução. Nas 45 páginas dessa Introdução, José de Bragança põe de maneira ensaística uma série de questões das mais importantes para a compreensão não só da gênese da Crônica de Zurara, mas também para a compreensão da gênese dos próprios Descobrimentos, e Expansão do século XV. Quarenta e cinco páginas das mais sugestivas que têm sido escritas sôbre o assunto.

A terceira, e última edição portuguêsa, até à presente data, da Crônica de Zurara aparece em 1949 sob a responsabilidade da Agência Geral das Colônias (atual Agência Geral do Ultramar), e com o título de Crônlica dos feitos de Guiné. Esta edição, segundo a Nota Explicativa que a precede, foi dirigida pelo então Diretor do Arquivo Histórico Colonial, que

"fêz compor e imprimir o texto e notas da editio princeps de Paris, 1841, dirigida, anotada e prefaciada pelo Visconde de Santarém, com glossário de J. I. Roquete" (!!!) .

Por despacho Ministerial de 31 de março de 1947 a Agência Geral das Colônias incumbiu de promover o acabamento da mencionada edição A. J. Dias Dinis, O.F.M. Este, autor de um volumoso livro sôbre a Vida e Obras de Gomes Eanes de Zurara que antecede esta edição em jeito de introdução, procura, com o auxílio das fotocópias do Manuscrito de Paris, corrigir tão lamentável edição. Dias Dinis acrescenta ao volume 
mais de trezentas erratas, contentando-se, nas suas próprias palavras, em "registar as mais importantes"...

Antes de chegar às traduções da Crônica de Zurara não nos esquecemos de mencionar os excertos publicados por Vitorino Magalhães Godinho no seus volumes de Documentos sôbre a Expansão Portuguêsa (3 volumes, publicados em Lisboa em 1943, 1944 e 1945). Vitorino Magalhães Godinho dános os textos de Zurara com a ortografia modernizada, e um comentário crítico que enfileira ao lado do que de melhor se fêz sôbre a tão discutida Crônica.

Vejamos agora as traduções elaboradas até à presente data.

A primeira tradução de excerto da Crônica é-nos dada por Ferdinand Denis na publicação em que anuncia o seu achado, nas Chroniques chevaleresques de l'Espagne et du Portugal, publicadas em Paris, em 1839. Ali vemos traduzido para francês, de páginas 45 a 49, o Capítulo XXV da Crônica, sôbre a partilha dos escravos em Lagos, com o título: Le premier jour de la traite à Lagos.

Em 1896, data em que ainda existia apenas a primeira edição portuguêsa, publicada em Paris, em 1841, pelo Visconde de Santarém, surge a primeira tradução completa, em língua inglêsa, com uma Introdução e comentários críticos. Trata-se de obra de Charles Raymond Beazley e Edgar Prestage, realizada para a explêndida coleção da Hakluyt Society, com o título: The Chronlicle of the Discovery \& Conquest of Guinea, Written by Gomes Eannes de Azurara, em 2 volumes. Trata-se de um trabalho pioneiro, inteiramente dentro dos moldes de seriedade da prestigiosa coleção que o fêz surgir, e apenas cum as limitações que o tempo, o tempo já passado, lhe fêz aparecer.

Em 1934, Virgínia de Castro e Almeida, na coleção Les Grands Navigateurs et Colons Portugais du XV et XVI siècles, Éditions Ducharte, de Paris, publica as Chroniques de Gomes Eannes de Azurara: la conquête de Ceuta; la découverte de la Guinée, com um prefácio do Marechal Lyautey (páginas XI a XIV). Nesta obra, vemos: Notes sur l'Histoire du Portugal (páginas 3 a 10), de Virgínia de Castro e Almeida; Chronique du roi Dom João I (páginas 13 a 82); Extrait de l'Introduction à l'édition de 1841 par le Vicomte de Santarém (páginas 85 e 8f); Chronique de la Découverte de la Guinée (páginas 87 a 198). Esta tradução em língua francesa de uma grande parte da Crônica dos feitos de Guiné é entremeada com o resumo de extensos passos. Vêm-se também notas em fim de página que reproduzem as da edição do Visconde de Santarém. 
Esta coletânea de Virgínia de Castro e Almeida foi traduzida para inglês em 1936 e publicada em Londres: Conquests \& Discoveries of Henry the Navigator being the Chronicles of Zurara, edited by Virginia de Castro e Almeida, with a Preface by Marschal Lyautey.

Finalmente, a última tradução, para a língua francesa, do texto integral da Crônica, com uma Introdução, e um completíssimo comentário crítico: Léon Bourdon (avec la collaboration de Robert Ricard, E. Serra Rafols, Théodore Monod, Raymond Mauny, Guy Beaujouan - Gomes Eanes de Zurara: Chronique de Guinée, Dakar, 1960. As notas de comentário desta tradução crítica são indiscutivelmente o que de melhor se fêz no gênero sôbre a célebre Crôníca de Zurara. A Introdução, da exclusiva responsabilidade de Léon Bourdon ,aparece-nos. como um dos melhores estudos sôbre a Crônica, alinhando com cs trabalhos de mérito invulgar que nos deram Joaquim de Carvalho, Costa Pimpão, Duarte Leite, Margarida Barradas de Carvalho. Léon Bourdon, de posse de uma bibliografia que podemos classificar de exaustiva, dá-nos com uma seriedade que só peca às vêzes por demasiada prudência, o estado atual das controvérsias que têm surgido a propósito de vários problemas que, dizendo respeito à obra de Zurara, a transcendem em muitos casos. Para terminar esta breve nota poderemos dizer que, entre os problemas abordados, um existe que merece referência especial, pois Léon Bourdon trouxe um elemento nôvo, talvez decisivo, para a sua solução. Trata-se do tão discutido problema da data de redação da Crônica, que seria na verdade aquela que nos dá nas últimas linhas o Manuscrito de Paris: 1453.

JOAQUIM BARRADAS DE CARVALHO Professor de História Ibérica da Faculdade de Filosofia, Ciências e Letras da Universidade de São Paulo 